\title{
Irisin enhances osteogenic differentiation of mouse MC3T3-E1 cells via upregulating osteogenic genes
}

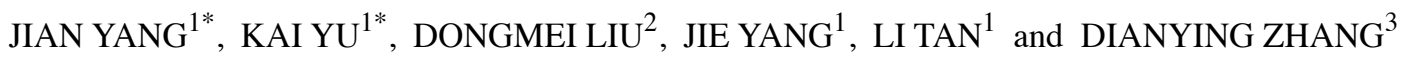 \\ Departments of ${ }^{1}$ Orthopaedics and ${ }^{2}$ Endocrinology, Tianjin Fifth Central Hospital, Tianjin 300450; \\ ${ }^{3}$ Department of Orthopaedics, Peking University People's Hospital, Beijing 10000, P.R. China
}

Received July 15, 2020; Accepted November 11, 2020

DOI: $10.3892 /$ etm.2021.10012

\begin{abstract}
Osteoporosis affects millions of individuals and remains a clinical challenge in terms of prevention and treatment. The present study aimed to investigate the effect of irisin on osteogenic differentiation by exposing MC3T3-E1 cells to different concentrations of irisin. Treated cells were assayed for osteoblast proliferation and osteogenic differentiation by measuring alkaline phosphatase (ALP) activity, calcium deposition, formation of mineralized nodules and the expression of osteogenic genes using reverse transcription-quantitative PCR. The proliferation of MC3T3-E1 cells was unaffected by irisin at the concentrations tested of up to $100 \mathrm{ng} / \mathrm{ml}(\mathrm{P}>0.05)$. ALP activity and mineralized nodule formation were significantly enhanced by irisin in a dose- and time-dependent manner, indicating that irisin promotes osteoblast differentiation of MC3T3-E1 cells. The expression of osteogenic genes, including ALP, collagen I, runt-related transcription factor 2, osterix, osteopontin, osteocalcin, osteoprotegerin and estrogen receptor $\alpha$, increased significantly after irisin treatment. The present study demonstrated that irisin promoted the osteogenic differentiation of MC3T3-E1 cells, possibly by upregulating the expression of osteogenic genes and markers. Therefore, irisin may be worthy of further investigation as a potential therapeutic agent for osteoporosis.
\end{abstract}

Correspondence to: Dr Dianying Zhang, Department of Orthopaedics, Peking University People's Hospital, 11 Xizhimen South Street, Beijing 10000, P.R. China

E-mail: d2212111@163.com

${ }^{*}$ Contributed equally

Abbreviations: ALP, alkaline phosphatase; RT-qPCR, reverse transcription-quantitative PCR; OP, osteoporosis; BMD, bone mineral density; RANKL, receptor activator of nuclear factor- $\kappa \mathrm{B}$ ligand; NS, normal saline; ARS, alizarin red S; pNPP, p-nitrophenyl phosphate; COL-1, collagen I; OCN, osteocalcin; OPN, osteopontin; $\mathrm{ER} \alpha$, estrogen receptor $\alpha$; BM-MSC, bone marrow mesenchymal stem cell; OSX, osterix; OPG, osteoprotegerin

Key words: irisin, osteogenic differentiation, cell proliferation, osteogenic markers, osteoporosis

\section{Introduction}

Osteoporosis (OP) is a chronic disease characterized by decreased bone strength, which predisposes affected individuals to fractures (1). With the aging population, it represents a growing global public health problem. In the US, among adults aged $\geq 50$ years, $\sim 10.3 \%$ or 10.2 million had OP of the lumbar spine or femoral neck and $43.9 \%$ or 43.4 million had osteopenia at skeletal sites in 2010 (2). The medical expenses for OP management place a heavy financial burden on society and individuals (3). For instance, $>1.7$ million patients were admitted to hospital with fragility fractures in 2011 and the direct costs associated with OP treatment exceeded $\$ 70$ billion in the US (4).

Pharmaceuticals that improve bone mineral density (BMD) are used as the first-line treatment for OP. However, due to poor compliance, high medical costs and negative side effects, the overall outcomes remain limited (5) and exercise training is one of the proven alternative strategies that improves multiple skeletal structures and reduces the fall risk simultaneously (6). Agents currently approved for OP treatment, such as calcium and vitamin $\mathrm{D}$, have the major function of inhibiting bone resorption. However, once OP is developed, substantial increases in bone mass may be necessary to reverse the disease. Therefore, it is necessary to develop therapeutics that increase bone formation (7).

To date, various pharmacological treatments for osteoporosis have been proven to reduce fracture risks, including bisphosphonates, selective estrogen receptor modulators, the monoclonal antibody against the receptor activator of nuclear factor- $\mathrm{kB}$ ligand (RANKL) (8). Numerous herbal medicines derived from natural products have been used in the treatment of osteoporosis with relatively few negative effects (9). In addition, several bioactive components have been identified for alternative treatments of OP (9) and a large number of them promote osteogenic differentiation via osteoblast activation (10). These therapeutic agents have been proven to promote osteogenesis with osteoblasts as the target $(11,12)$.

Irisin is a newly discovered myokine produced during exercise (13). It drives brown fat-like development of white fat to generate thermal energy. Previous studies have indicated that irisin exerts the beneficial effect of exercise on metabolic diseases such as diabetes, obesity and osteoporosis $(14,15)$. The level of irisin in plasma was determined to be related to 
BMD in the elderly (16), implying that it has a role in bone development. Recently, irisin has been demonstrated to promote osteoblast differentiation and mineralization in rat osteoblasts and MC3T3-E1 cells. It upregulates the expression of osteoblastic transcription regulators, such as runt-related transcription factor-2 (RUNX2), osterix (OSX)/sp7 and differentiation markers, such as alkaline phosphatase (ALP) (17). However, the receptor for irisin has not been identified, although it is suggested that irisin may activate P38/ERK MAP kinase signaling cascades to promote osteogenic activity (17). In addition, Colaianni et al (18) reported that excise increases irisin levels in mouse myoblasts and that media conditioned with the myoblasts extracted from exercised mice induces osteoblast differentiation in vitro, demonstrating that irisin directly targets osteoblasts. Besides osteoblasts, irisin was also indicated to promote osteogenic activity of human periodontal ligament cells by enhancing extracellular matrix formation, indicating its potential for dental tissue engineering (19). Since irisin is released during excise and its level is related to BMD, it was hypothesized that it may be explored for potential use in the prevention and treatment of OP.

In the present study, the effect of irisin on osteogenic differentiation was investigated using MC3T3-E1 cells. This cell line is one of the most common cell lines for studying osteoblast proliferation and differentiation (20). It was established from newborn mouse calvaria and selected on the basis of high ALP activity during differentiation into osteoblasts in vitro. The present results provide insight into the roles of irisin in osteogenesis and clues for potential therapeutics for OP.

\section{Materials and methods}

Cells. Mouse calvaria-derived pre-osteoblast cell line MC3T3-E1 (CL-0378) was purchased from Procell Life Science \& Technology Co., Ltd. and maintained in Dulbecco's modified Eagle's medium (DMEM) supplemented with $10 \%$ fetal bovine serum (FBS) and 1\% penicillin-streptomycin in $5 \% \mathrm{CO}_{2}$ at $37^{\circ} \mathrm{C}$. Cells were grown to $85 \%$ confluence and subcultured as previously described (21).

Reagents and instruments. Irisin was purchased from Phoenix Pharmaceuticals, Inc.; DMEM was obtained from Thermo Fisher Scientific, Inc.; Minimal Essential Media and FBS were obtained from HyClone (Cytiva); human mesenchymal stem cell osteogenic differentiation medium (cat. no. PT-3002) was purchased from Lonza Group Ltd.; the ALP quantification kit and MTT (cat. no. C0009) were obtained from Beyotime Institute of Biotechnology; the RNA reverse-transcription kit was a product of Invitrogen (Thermo Fisher Scientific, Inc.); alizarin red S (ARS) staining solution was purchased from Beijing Solarbio Science \& Technology Co., Ltd.; the High Capacity cDNA Transcriptase Reverse kit was purchased from Applied Biosystems (Thermo Fisher Scientific, Inc.); the SYBR Green PCR kit was obtained from Takara Bio, Inc.; the UV spectrophotometer Evolution 201/220 was purchased from Thermo Fisher Scientific, Inc.; the fluorescence quantitative (q)PCR instrument LightCycler96 was purchased from Roche Diagnostics; the PCR thermal cycler PTC-200 was purchased from MJ Research, Inc. (Bio-Rad Laboratories, Inc.); the inverted microscope (Eclipse TS100) was a product of Nikon
Corp. and the plate reader (Triad LT Multimode Detector) was obtained from Dynex Technologies, Inc.

Cell culture and osteogenic differentiation. MC3T3-E1 cells at the third passage were used in the experiments. At $24 \mathrm{~h}$ after the cells were seeded in wells of 24 -well plates at $2 \times 10^{4}$ cells/well, the growth media were replaced with commercial osteogenic differentiation medium containing inducers and growth factors (included in the commercial medium), including dexamethasone, ascorbate, $\beta$-glycerophosphate and mesenchymal cell growth supplement, L-glutamine and $1 \%$ penicillin/streptomycin and cultured in a humidified atmosphere with $5 \% \mathrm{CO}_{2}$ at $37^{\circ} \mathrm{C}$. Irisin was dissolved in sterile normal saline (NS) at $100 \mu \mathrm{g} / \mathrm{ml}$ and filter-sterilized using a membrane filter with a pore size of $0.22 \mu \mathrm{m}$. It was added to the medium at final concentrations of up to $100 \mathrm{ng} / \mathrm{ml}$ from the beginning of the experiments. NS was used as a control. Media were refreshed every 3 days. All of the cultures were grown for 21 days and then harvested for assessing the osteogenic markers. Cell cultures were collected and stored at $-80^{\circ} \mathrm{C}$ prior to RNA extraction. For each treatment, six wells (samples) were used and all experiments were performed for a total of three times.

MTT assay. MTT assays were performed according to the manufacturer's protocols, as described previously (22). In brief, cells were seeded $\left(1 \times 10^{5}\right.$ cells/well $)$ in 96-well plates and exposed to irisin for $48 \mathrm{~h}$ at $37^{\circ} \mathrm{C}$. After treatment, $20 \mu \mathrm{l} \mathrm{MTT}$ solution was added to each well and the plate was incubated for $4 \mathrm{~h}$ at $37^{\circ} \mathrm{C}$. The reaction was stopped by adding $150 \mu \mathrm{l}$ DMSO to dissolve the purple formazan dye precipitate, after the media/MTT solution had been removed. The absorbance was read at $490 \mathrm{~nm}$ using a plate reader (Triad LT Multimode Detector; Dynex Technologies, Inc.). Cell viability was normalized using NS-treated cells as a control and calculated as described previously (22).

ALP activity assays. After exposure to medium containing irisin, ALP activity was measured colorimetrically with a commercial ALP colorimetric assay kit using p-nitrophenyl phosphate (pNPP) as the phosphatase substrate according to the supplier's protocols and as described previously (23). In brief, cell lysates were prepared using three cycles of freeze-thawing. Subsequently, $30 \mu \mathrm{l}$ of the cell lysate was added to each well of a 96-well plate with $50 \mu \mathrm{l}$ assay buffer and $50 \mu \mathrm{l} \mathrm{pNPP}$. The samples were incubated at room temperature for $1 \mathrm{~h}$. After this, $20 \mu$ stop solution $(3 \mathrm{~N} \mathrm{NaOH})$ was added to the wells and the plates were read at a wavelength of $405 \mathrm{~nm}$ with the plate reader. The protein concentrations in the samples were determined using a bicinchoninic acid assay (Pierce; Thermo Fisher Scientific, Inc.) according to the supplier's protocol.

ARS staining and quantification of calcium deposits. ARS staining was used to detect calcium mineralization according to the manufacturer's protocol. In brief, cells $\left(1 \times 10^{5}\right)$ were rinsed with PBS, fixed with $4 \%$ formaldehyde $(\mathrm{m} / \mathrm{v})$ in PBS for $30 \mathrm{~min}$, washed with deionized water and stained for 30 min with $0.5 \%$ ARS (w/v in water; $\mathrm{pH} 6.36-6.4)$ at $37^{\circ} \mathrm{C}$. Subsequently, the cells were washed with water and viewed under an inverted microscope (magnification, x100). Calcium deposits were observed as orange and red spots. For staining 
Table I. PCR primers for osteogenic genes.

\begin{tabular}{|c|c|}
\hline $\begin{array}{l}\text { Gene/primer } \\
\text { direction }\end{array}$ & Sequence \\
\hline \multicolumn{2}{|l|}{ ALP } \\
\hline Forward & 5'-CAGACCAGCACACTCCATA-3' \\
\hline Reverse & 5'-CAGCTCAACACCATCATTC-3' \\
\hline \multicolumn{2}{|l|}{ OSX } \\
\hline Forward & 5'-AGAAGCCATACACTGACCTTTC-3' \\
\hline Reverse & 5'-GGTGGGTAGTCATTGGCATAG-3' \\
\hline \multicolumn{2}{|l|}{ RUNX2 } \\
\hline Forward & 5'-ACTTCCTGTGCTCCGTGCTG-3' \\
\hline Reverse & 5'-TCGTTGAACCTGGCTACTTGG-3' \\
\hline \multicolumn{2}{|l|}{$\mathrm{ER} \alpha$} \\
\hline Forward & 5'-CGCCGTGTTCAACTAC-3' \\
\hline Reverse & 5'- AAGCCCCCAGACTATT-3' \\
\hline \multicolumn{2}{|l|}{ COL-1 } \\
\hline Forward & 5'-GGGTCTAGACATGTTCAGCTTTGTG-3' \\
\hline Reverse & 5'-ACCCTTAGGCCATTGTGTATGC-3' \\
\hline \multicolumn{2}{|l|}{$\mathrm{OCN}$} \\
\hline Forward & 5'-CAAGCAGGAGGGCAATAAGGT-3' \\
\hline Reverse & 5'-AGCAGGGTCAAGCTCACATAG-3' \\
\hline \multicolumn{2}{|l|}{ OPN } \\
\hline Forward & 5'-CCCATCTCAGAAGCAGAATCTT-3' \\
\hline Reverse & 5'-GTCATGGCTTTCATTGGAGTTG-3' \\
\hline \multicolumn{2}{|l|}{ OPG } \\
\hline Forward & 5'-CAAAGGCAGGGCATACTTC-3' \\
\hline Reverse & 5'-TTCAATGATGTCCAAGAACACC-3' \\
\hline \multicolumn{2}{|l|}{$\beta$-actin } \\
\hline Forward & 5'-CTGTCCCTGTATGCCTCTG-3' \\
\hline Reverse & 5'-TGATGTCACGCACGATTT-3' \\
\hline
\end{tabular}

ALP, alkaline phosphatase; Osx, osterix; RUNX2, runt-related transcription factor-2; ER $\alpha$, estrogen receptor $\alpha$; COL-1, collagen I; OCN, osteocalcin; OPN, osteopontin; OPG, osteoprotegerin.

quantification, the deposits were eluted with $20 \%$ (v/v) methanol and $10 \%(\mathrm{v} / \mathrm{v})$ acetic acid. The absorbance of the extract was determined at $450 \mathrm{~nm}$ wavelength with the plate reader as described previously (24).

Reverse transcription $(R T)-q P C R$. To detect the expression of osteogenesis-related genes, total RNA was extracted from MC3T3-E1 cells using TRIzol reagent, according to the supplier's protocols, and reverse transcribed to complementary (c)DNA using the High Capacity cDNA Transcriptase Reverse kit, according to the manufacturer's protocols. The transcription levels were determined by qPCR using the SYBR Green PCR kit on the thermal cycler PTC-200. The PCR reaction mixtures contained $1 \mu \mathrm{l}$ cDNA, $10 \mu 1 \mathrm{SYBR}^{\circledR}$ Premix Ex Taq and $0.25 \mu \mathrm{M}$ each of the primers in a total volume of $25 \mu \mathrm{l}$. The PCR started with initial DNA denaturation at $95^{\circ} \mathrm{C}$ for $30 \mathrm{sec}$, followed by 40 cycles of $33 \mathrm{sec}$ at $95^{\circ} \mathrm{C}$ and $4 \mathrm{~min}$ at $60^{\circ} \mathrm{C}$. The data were managed using the Applied Biosystems software

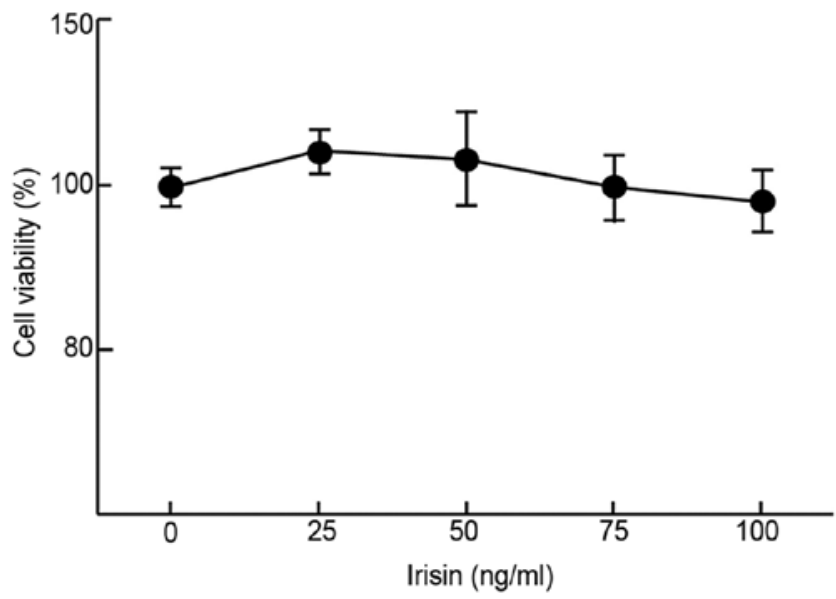

Figure 1. Viability of MC3T3-E1 cells grown in medium supplemented with different concentrations of irisin.

RQ Manager v1.2.1 (Thermo Fisher Scientific, Inc.). Relative expression was calculated by using comparative quantification cycle $(\mathrm{Cq})$ method to obtain the fold change value $\left(2^{-\Delta \Delta \mathrm{Cq}}\right)$ according to a previously described protocol (25) with $\beta$-actin as the reference gene. The primers used for PCR are listed in Table I. Three samples were measured in each experiment of reverse transcription and PCR amplification.

Statistical analysis. Statistical analysis was performed using SPSS v19.0 (IBM Corp.). All data were expressed as the mean \pm standard error of the mean obtained from at least three independent experiments. Statistical comparisons between groups were assessed using one-way ANOVA followed by a Tukey's post-hoc test. $\mathrm{P}<0.05$ was considered to indicate a statistically significant difference.

\section{Results}

Irisin does not affect the proliferation of MC3T3-E1 cells. The impact of irisin on the growth/viability of MC3T3-E1 cells in vitro was examined using MTT assays to evaluate its possible cytotoxicity. The results suggested that irisin did not have any significant impact on the viability of MC3T3-E1 cells at up to $100 \mathrm{ng} / \mathrm{ml}$ as compared to the negative control $(99 \pm 4.8 \%$ at $100 \mathrm{ng} / \mathrm{ml}$ vs. $100 \pm 2.7 \%$ at $0 \mathrm{ng} / \mathrm{ml}$; Fig. 1) after incubation for $48 \mathrm{~h}$. At low concentrations (50 $\mathrm{ng} / \mathrm{ml}$ or less), it slightly but insignificantly increased the cell viability as compared with the control $(112 \pm 3.1$ and $105 \pm 7.5 \%$ at 25 and $50 \mathrm{mg} / \mathrm{ml}$, respectively, vs. $100 \%$ at $0 \mathrm{ng} / \mathrm{ml}$; Fig. 1).

Irisin increases the ALP activity and promotes the formation of mineralized nodules. ARS staining indicated calcium-rich deposits in the cells starting after culturing the cells in the osteogenic medium for one week (Fig. 2). The formation of mineralized nodules was observed after MC3T3-E1 cells were cultured in osteogenic medium for one week and became clearly visible at three weeks even with the naked eye (Fig. 2). Assessment of ALP activity in MC3T3-E1 cells suggested that the ALP enzymatic activity increased from $3.51 \pm 0.76$ to $22.82 \pm 2.05 \mathrm{U} / \mathrm{mg}$ on day 7 as the concentration of irisin increased from 0 to $100 \mathrm{ng} / \mathrm{ml}$, 


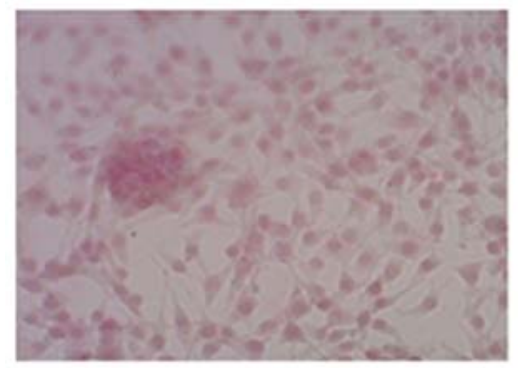

Irisin $0 \mathrm{ng} / \mathrm{ml}$

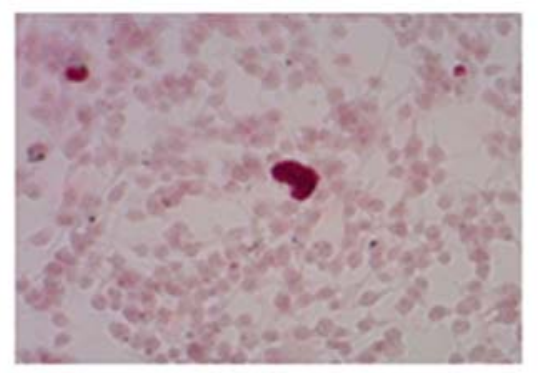

Irisin $50 \mathrm{ng} / \mathrm{ml}$

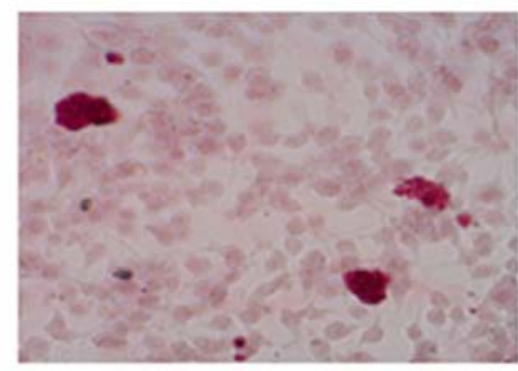

Irisin $100 \mathrm{ng} / \mathrm{ml}$

Figure 2. Mineralized nodule formation in cultured MC3T3-E1 cells grown in medium with different levels of irisin (magnification, x100; staining with Alizarin Red).

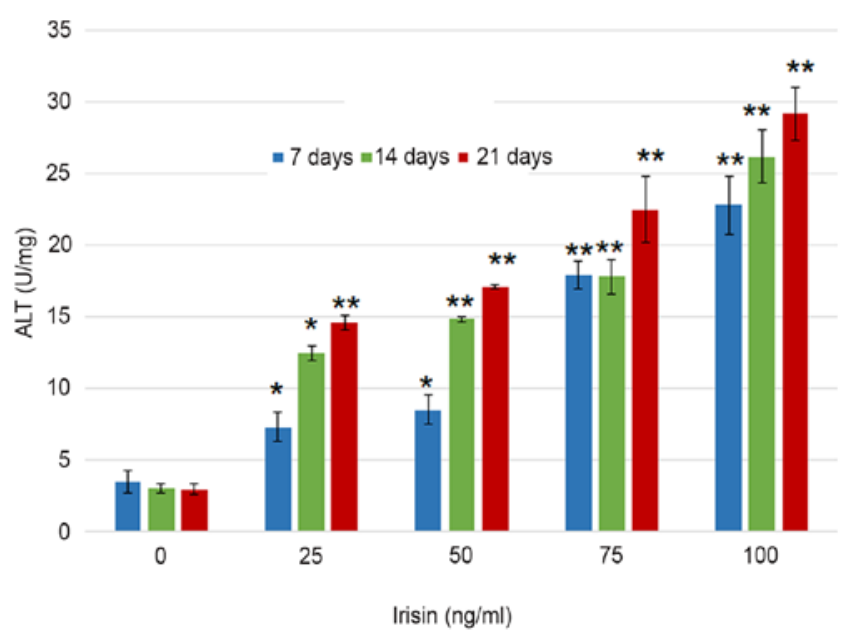

Figure 3. Effect of irisin on the ALP enzymatic activity in cultured MC3T3-E1 cells grown in medium with different levels of irisin. ${ }^{*} \mathrm{P}<0.05$; ${ }^{* *} \mathrm{P}<0.01$ vs. control ( $0 \mathrm{ng} / \mathrm{ml}$ irisin). ALP, alkaline phosphatase.

and from $22.82 \pm 2.05$ to $29.1 \pm 1.86 \mathrm{U} / \mathrm{mg}$ at $100 \mathrm{mg} / \mathrm{ml}$ irisin as the culture time increased from 7 to 21 days (Fig. 3). The increase over time appeared more notable at the low irisin concentrations of 25 and $50 \mathrm{ng} / \mathrm{ml}$. However, the enzymatic activity of ALP was not significantly changed over the culture period with irisin. Analyses suggested that calcium deposits increased in an irisin concentration- and time-dependent manner ( $\mathrm{P}<0.05$; Fig. 4). On day 7, calcium in MC3T3-E1 cells increased from 209.30 $\pm 7.24 \mathrm{nmol} /$ well at $0 \mathrm{mg} / \mathrm{ml}$ irisin to $1,153.65 \pm 25.51 \mathrm{nmol} / \mathrm{well}$ at $100 \mathrm{mg} / \mathrm{ml}$ and this trend was seen on days 14 and 21 , and the amount of ARS increased as the culture time increased. On the other hand, calcium contents in the control group only exhibited an insignificant increase over the experimental period (P>0.05; Fig. 4).

Irisin upregulates the expression of osteogenic genes and markers. To elucidate the mechanisms underlying the enhanced osteogenic activity stimulated by irisin, the expression of osteogenic genes and markers was assessed using RT-qPCR. After exposure to irisin for 21 days, the mRNA levels of ALP, collagen I (COL-1), RUNX2, OSX, osteopontin (OPN), osteocalcin $(\mathrm{OCN})$, osteoprotegerin (OPG) and estrogen receptor $\alpha$ $(\mathrm{ER} \alpha)$ were all significantly increased $(\mathrm{P}<0.05$ or $\mathrm{P}<0.01)$ as compared with those in the control. Among them, the upregu-

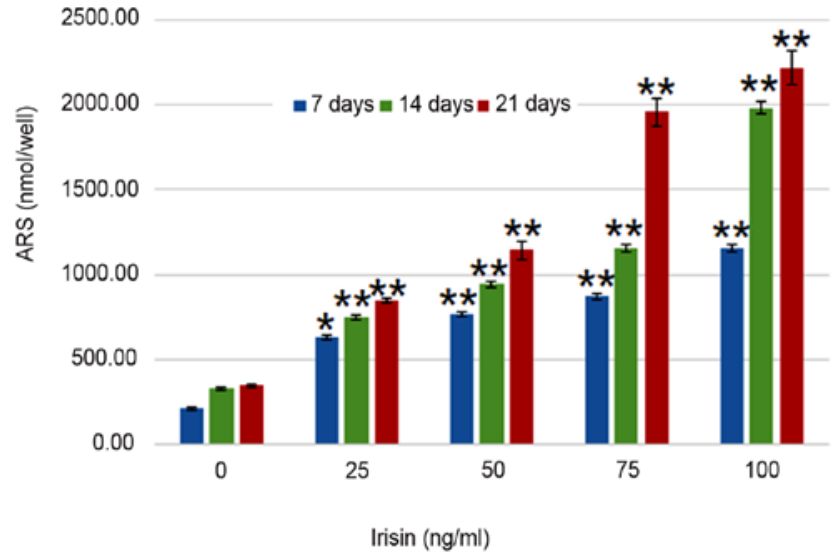

Figure 4. Effect of irisin on calcium deposits in cultured MC3T3-E1 cells grown in medium different levels of irisin. ${ }^{*} \mathrm{P}<0.05$; ${ }^{* *} \mathrm{P}<0.01$ vs. control ( $0 \mathrm{ng} / \mathrm{ml}$ irisin). ARS, alizarin red $\mathrm{S}$.

lations were more obvious for ALP, OPN, OPG, Er $\alpha$ and OSX, but less intense for OCN (Fig. 5).

\section{Discussion}

In vitro osteogenic differentiation may be detected and assessed in several ways, including measuring ALP enzymatic activity, extracellular matrix mineralization and levels of osteogenesis related genes, such as OSX, RUNX2, BMP-2, OPN, COL-1, OCN, OPG and ALP (26). Several of these genes are considered as osteogenic markers, which have important roles during early osteoblastic differentiation and late mineralization (27) and were chosen to measure the osteogenic induction ability of irisin in the present study. The results indicated that irisin increased the enzymatic activity of ALP and calcium deposits, and promoted the differentiation of MC3T3-E1 cells into osteoblasts and the formation of mineralized nodules in cultured MC3T3-E1 cells. At the molecular level, it upregulated the expression of osteogenesis-related genes and markers. Furthermore, at the concentrations used, it did not have a significant negative impact on the viability of MC3T3-E1 cells. Therefore, the peptide may be further explored as a potential candidate for OP therapy.

Osteogenesis is a complex biological process where a number of genes are involved in shaping the direction of differentiation. It has been demonstrated that early/late osteoblastic 

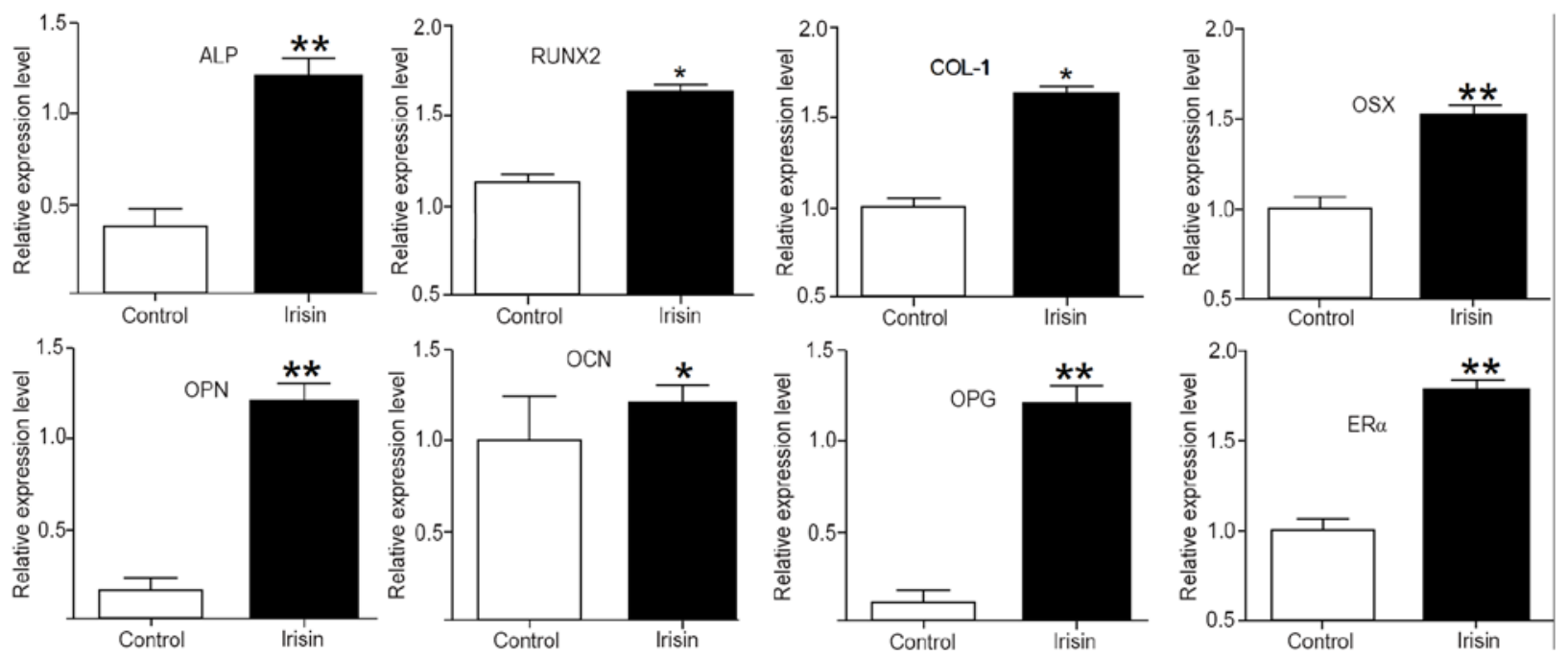

Figure 5. Effect of irisin on the expressions of osteogenic genes and markers in MC3T3-E1 cells after exposing MC3T3-E1 cells to $100 \mathrm{ng} / \mathrm{ml}$ irisin for $21 \mathrm{days}$. ${ }^{*} \mathrm{P}<0.05 ;{ }^{* *} \mathrm{P}<0.01$ vs. control. ALP, alkaline phosphatase; RUNX2, runt-related transcription factor-2; COL-1, collagen I; OSX, osterix; OPN, osteopontin; OCN, osteocalcin; OPG, osteoprotegerin; ER $\alpha$, estrogen receptor $\alpha$.

proliferation and differentiation may be estimated by assessing the expression of COL-I, ALP, OCN and OPN, although these markers have not been demonstrated to indicate the differentiation of MC3T3-E1 cells towards the osteogenic lineage (27). ALP is associated with a perosseous cellular metabolism and to the elaboration of a bone matrix that is chemically calcifiable (28). The activity of ALP increases during osteogenic differentiation in various cell types, such as mesenchymal stem cells (29). In the present study, MC3T3-E1 cells exposed to irisin had significantly higher ALP activity than the control cells, suggesting that irisin increases ALP activity, likely via upregulating the expression of the ALP gene, as indicated by RT-qPCR analysis.

RUNX2 was significantly upregulated in the cells grown in irisin-supplemented medium. As a major transcription factor of the bone, RUNX2 is essential for the differentiation of pluripotent mesenchymal cells to osteoblasts and also controls the proliferation, differentiation and maintenance of these cells (30). It is regarded as an early specific biomarker for osteogenic differentiation of osteoblasts. However, since its expression was assessed 21 days after the cells were exposed to irisin in the present study, further study is required to demonstrate its role in early osteogenic differentiation.

Collagens are the major components of bone matrix and other connective tissues (31). A previous study indicated that insulin-like growth factor I and transforming growth factor- $\beta 1$ promote osteoblast differentiation via upregulating COL-1, which, on the other hand, inhibits the production of osteoblasts in vitro (32). In the present study, increased COL-1 expression was observed. It would be worthwhile investigating whether such an increase is able to reduce the proliferation of osteoblasts simultaneously. Furthermore, the biological action of collagen is impacted by the interactions with other bone materials, such as glycosaminoglycan and minerals. When crosslinked with chitosan and hydroxyapatite, it may form a matrix that enhances bone growth and reduces bone resorption (33). Therefore, it is likely that COL-1 expression has a role in the later stage of osteogenesis.
OSX, also known as transcription factor Sp7, is a member of the Sp family of zinc-finger transcription factors. Along with RUNX2, it functions as a major player to drive the differentiation of mesenchymal precursor cells into osteoblasts and eventually osteocytes (34). A recent study indicated that OSX may be activated by long non-coding RNA MALAT1 to promote osteogenic differentiation of human BM-MSCs (35). This is consistent with the present results.

As a multifunctional protein, OPN has a crucial role in bone remodeling and biomineralization. It has been indicated to have a regulatory effect on hydroxyapatite crystal growth and may activate the signaling pathways mediated by various osteogenic genes, including OPN, bone sialoprotein, OSX and OCN (36). OCN, also known as bone $\gamma$-carboxyglutamic acid-containing protein, is specifically synthesized and secreted by osteoblasts in the non-proliferative phase. Generally, OCN is accumulated after the peak period of bone mineralization and is regulated by RUNX2. In the present study, OCN was relatively less upregulated as compared with the other osteogenic genes assessed. This may be attributed to the timing of the assay, since this gene may be more active after bone mineralization.

The RANK/RANKL/OPG axis has an important role in osteoclast regulation and bone homeostasis. Knockout of OPG, the soluble decoy receptor for RANKL, was indicated to generate profound osteoporosis (37). In addition, OPG reduces osteoclast resorption on mineralized collagen scaffolds (38). Therefore, increased OPG expression changes the balance of osteogenic-osteoclastic functions and results in osteogenic differentiation, probably via increasing the activity of the Wnt/ $\beta$-catenin pathway (39).

$E R \alpha$ and $E R \beta$ have been indicated to influence osteogenic differentiation of bone marrow mesenchymal stem cells (BM-MSCs). For instance, simvastatin-induced osteogenesis of BM-MSCs is mediated via an ER $\alpha$-dependent pathway (40). They are involved in bone-cell responses to mechanical stress that stimulate osteoblast proliferation and bone formation (41). As a mechanism of the isopsoralen-induced anti-osteoporotic 
effects, ER $\alpha$ promotes osteoblast differentiation and mineralization, increases calcium nodule levels and ALP activity and upregulates osteoblast markers (42). On other hand, ER inhibitor is able to significantly reduce the expression of the RUNX2, OSX and OPN genes and block osteogenic differentiation (43).

Taken together, the present results indicated that osteogenic activity stimulated by irisin is accompanied with upregulated expression of osteogenesis-related genes. However, the temporal and spatial patterns of expression require further investigation to elucidate the role and contributions of these genes in irisin-induced osteogenic differentiation. In addition, it is not clear the mechanism by which irisin acts to regulate the expression of these genes, although irisin is able to activate P38/ERK MAP kinase signaling cascades, leading to increased osteogenic activity (17). Furthermore, further in vitro and in vivo studies using different cells, animal models and human subjects are required to validate the present results and to develop irisin into a potential therapeutic agent for OP.

In conclusion, the present study demonstrated that irisin induces the differentiation of calvaria-derived pre-osteoblast cells into osteoblasts and the formation of mineralized nodules in vitro. This activity appears to be dose-dependent and is mediated by the activation of a number of osteogenesis-associated genes. Further studies are required to investigate the role of irisin in osteogenesis in vivo and determine its potential as a therapeutic for OP.

\section{Acknowledgements}

Not applicable.

\section{Funding}

No funding was received.

\section{Availability of data and materials}

The datasets used and/or analyzed during the current study are available from the corresponding author on reasonable request.

\section{Authors' contributions}

JY, KY and DZ designed the study. JY, KY, DZ, DL, JY and LT collected the data and performed the analysis. JY, KY and DZ drafted the manuscript. All authors read and approved the final manuscript.

\section{Ethics approval and consent to participate}

Not applicable.

\section{Patient consent for publication}

Not applicable.

\section{Competing interests}

The authors declare that they have no competing interests.

\section{References}

1. No authors listed: Osteoporosis prevention, diagnosis, and therapy. NIH Consens Statement 17: 1-45, 2000.

2. Ensrud KE and Crandall CJ: Osteoporosis. Ann Intern Med 168: 306-307, 2018

3. Tu KN, Lie JD, Wan CKV, Cameron M, Austel AG, Nguyen JK, Van K and Hyun D: Osteoporosis: a review of treatment options. P T 43: 92-104, 2018.

4. Ogdie A, Nowell WB, Applegate E, Gavigan K, Venkatachalam S, de la Cruz M, Flood E, Schwartz EJ, Romero B and Hur P: Patient perspectives on the pathway to psoriatic arthritis diagnosis: Results from a web-based survey of patients in the United States. BMC Rheumatol 4: 2, 2020.

5. Crandall CJ, Newberry SJ, Diamant A, Lim YW, Gellad WF, Booth MJ, Motala A and Shekelle PG: Comparative effectiveness of pharmacologic treatments to prevent fractures: An updated systematic review. Ann Intern Med 161: 711-723, 2014.

6. Cawthon PM, Fullman RL, Marshall L, Mackey DC, Fink HA, Cauley JA, Cummings SR, Orwoll ES and Ensrud KE; Osteoporotic Fractures in Men (MrOS) Research Group: Physical performance and risk of hip fractures in older men. J Bone Miner Res 23: 1037-1044, 2008.

7. Prestwood KM, Pilbeam CC and Raisz LG: Treatment of osteoporosis. Annu Rev Med 46: 249-256, 1995.

8. Cappola AR and Shoback DM: Osteoporosis therapy in postmenopausal women with high risk of fracture. JAMA 316: 715-716, 2016.

9. Park E, Kim J, Kim MC, Yeo S, Kim J, Park S, Jo M, Choi CW, Jin HS, Lee SW, et al: Anti-osteoporotic effects of kukoamine B isolated from Lycii radicis cortex extract on osteoblast and osteoclast cells and ovariectomized osteoporosis model mice. Int J Mol Sci 20: 20, 2019.

10. Li TM, Huang HC, Su CM, Ho TY, Wu CM, Chen WC, Fong YC and Tang $\mathrm{CH}$ : Cistanche deserticola extract increases bone formation in osteoblasts. J Pharm Pharmacol 64: 897-907, 2012.

11. Zhang J, Zhang W, Dai J, Wang X and Shen SG: Overexpression of Dlx2 enhances osteogenic differentiation of BMSCs and MC3T3-E1 cells via direct upregulation of Osteocalcin and Alp. Int J Oral Sci 11: 12, 2019.

12. Sasa K, Yoshimura K, Yamada A, Suzuki D, Miyamoto Y, Imai H, Nagayama K, Maki K, Yamamoto M and Kamijo R: Monocarboxylate transporter-1 promotes osteoblast differentiation via suppression of $\mathrm{p} 53$, a negative regulator of osteoblast differentiation. Sci Rep 8: 10579, 2018.

13. Boström P, Wu J, Jedrychowski MP, Korde A, Ye L, Lo JC, Rasbach KA, Boström EA, Choi JH, Long JZ, et al: A PGC1- $\alpha$-dependent myokine that drives brown-fat-like development of white fat and thermogenesis. Nature 481: 463-468, 2012.

14. Hofmann T, Elbelt U and Stengel A: Irisin as a muscle-derived hormone stimulating thermogenesis--a critical update. Peptides 54: 89-100, 2014.

15. Huh JY, Dincer F, Mesfum E and Mantzoros CS: Irisin stimulates muscle growth-related genes and regulates adipocyte differentiation and metabolism in humans. Int J Obes 38: 1538-1544, 2014.

16. Wu LF, Zhu DC, Tang CH, Ge B, Shi J, Wang BH, Lu YH, He P, Wang WY, Lu SQ, et al: Association of plasma irisin with bone mineral density in a large chinese population using an extreme sampling design. Calcif Tissue Int 103: 246-251, 2018.

17. Qiao X, Nie Y, Ma Y, Chen Y, Cheng R, Yin W, Hu Y, Xu W and $\mathrm{Xu}$ L: Irisin promotes osteoblast proliferation and differentiation via activating the MAP kinase signaling pathways. Sci Rep 6: $18732,2016$.

18. Colaianni G, Cuscito C, Mongelli T, Oranger A, Mori G, Brunetti G, Colucci S, Cinti S and Grano M: Irisin enhances osteoblast differentiation in vitro. Int J Endocrinol 2014: 902186 , 2014.

19. Pullisaar H, Colaianni G, Lian AM, Vandevska-Radunovic V, Grano $\mathrm{M}$ and Reseland JE: Irisin promotes growth, migration and matrix formation in human periodontal ligament cells. Arch Oral Biol 111: 104635, 2020.

20. Sudo H, Kodama HA, Amagai Y, Yamamoto S and Kasai S: In vitro differentiation and calcification in a new clonal osteogenic cell line derived from newborn mouse calvaria. J Cell Biol 96: 191-198, 1983.

21. Nagao M, Tanabe N, Manaka S, Naito M, Sekino J, Takayama T, Kawato T, Torigoe G, Kato S, Tsukune N, et al: LIPUS suppressed LPS-induced IL-1 $\alpha$ through the inhibition of NF- $\kappa B$ nuclear translocation via AT1-PLC $\beta$ pathway in MC3T3-E1 cells. J Cell Physiol 232: 3337-3346, 2017. 
22. Cheleschi S, Giordano N, Volpi N, Tenti S, Gallo I, Di Meglio M, Giannotti S and Fioravanti A: A complex relationship between visfatin and resistin and microrna: an in vitro study on human chondrocyte cultures. Int J Mol Sci 19: 19, 2018.

23. Sun J, Zhao J, Bao X, Wang Q and Yang X: Alkaline phosphatase assay based on the chromogenic interaction of diethanolamine with 4-aminophenol. Anal Chem 90: 6339-6345, 2018.

24. Palmieri V, Barba M, Di Pietro L, Conti C, De Spirito M, Lattanzi W and Papi M: Graphene oxide induced osteogenesis quantification by in-situ 2D-fluorescence spectroscopy. Int J Mol Sci 19: 19, 2018.

25. Livak KJ and Schmittgen TD: Analysis of relative gene expression data using real-time quantitative PCR and the 2(-Delta Delta C(T)) method. Methods 25: 402-408, 2001

26. Krause U, Seckinger A and Gregory CA: Assays of osteogenic differentiation by cultured human mesenchymal stem cells. Methods Mol Biol 698: 215-230, 2011.

27. Ching HS, Luddin N, Rahman IA and Ponnuraj KT: Expression of odontogenic and osteogenic markers in DPSCs and SHED: a review. Curr Stem Cell Res Ther 12: 71-79, 2017.

28. Siffert RS: The role of alkaline phosphatase in osteogenesis. J Exp Med 93: 415-426, 1951.

29. Birmingham E, Niebur GL, McHugh PE, Shaw G, Barry FP and McNamara LM: Osteogenic differentiation of mesenchymal stem cells is regulated by osteocyte and osteoblast cells in a simplified bone niche. Eur Cell Mater 23: 13-27, 2012

30. Ducy P, Zhang R, Geoffroy V, Ridall AL and Karsenty G: Osf2/Cbfa1: A transcriptional activator of osteoblast differentiation. Cell 89: 747-754, 1997.

31. Stadlinger B, Pilling E, Mai R, Bierbaum S, Berhardt R, Scharnweber D and Eckelt U: Effect of biological implant surface coatings on bone formation, applying collagen, proteoglycans, glycosaminoglycans and growth factors. J Mater Sci Mater Med 19: 1043-1049, 2008.

32. Schmidmaier G, Wildemann B, Lübberstedt $M$, Haas NP and Raschke M: IGF-I and TGF-beta 1 incorporated in a poly(D,L-lactide) implant coating stimulates osteoblast differentiation and collagen-1 production but reduces osteoblast proliferation in cell culture. J Biomed Mater Res B Appl Biomater 65: 157-162, 2003.

33. Elango J, Saravanakumar K, Rahman SU, Henrotin Y, Regenstein JM, Wu W and Bao B: Chitosan-collagen 3D matrix mimics trabecular bone and regulates RANKL-mediated paracrine cues of differentiated osteoblast and mesenchymal stem cells for bone marrow macrophage-derived osteoclastogenesis. Biomolecules 9: 9, 2019.
34. Hekmatnejad B, Gauthier C and St-Arnaud R: Control of Fiat (factor inhibiting ATF4-mediated transcription) expression by Sp family transcription factors in osteoblasts. J Cell Biochem 114: $1863-1870,2013$

35. Gao Y, Xiao F, Wang C, Wang C, Cui P, Zhang X and Chen X: Long noncoding RNA MALAT1 promotes osterix expression to regulate osteogenic differentiation by targeting miRNA-143 in human bone marrow-derived mesenchymal stem cells. J Cell Biochem 119: 6986-6996, 2018.

36. Singh A, Gill G, Kaur H, Amhmed M and Jakhu H: Role of osteopontin in bone remodeling and orthodontic tooth movement: A review. Prog Orthod 19: 18, 2018.

37. Simonet WS, Lacey DL, Dunstan CR, Kelley M, Chang MS, Lüthy R, Nguyen HQ, Wooden S, Bennett L, Boone T, et al: Osteoprotegerin: A novel secreted protein involved in the regulation of bone density. Cell 89: 309-319, 1997.

38. Ren X, Zhou Q, Foulad D, Tiffany AS, Dewey MJ, Bischoff D, Miller TA, Reid RR,He TC, Yamaguchi DT, et al: Osteoprotegerin reduces osteoclast resorption activity without affecting osteogenesis on nanoparticulate mineralized collagen scaffolds. Sci Adv 5: eaaw4991, 2019

39. Gao X, Zheng J, Tu S, Cai B, Zeng R and Xiang L: Role of osteoprotegerin in the regulation of dental epithelial mesenchymal signaling during tooth development. Mol Med Rep 20: 3035-3042, 2019.

40. Chuang SC, Chen CH, Fu YC, Tai IC, Li CJ, Chang LF, Ho ML and Chang JK: Estrogen receptor mediates simvastatin-stimulated osteogenic effects in bone marrow mesenchymal stem cells. Biochem Pharmacol 98: 453-464, 2015.

41. Galea GL, Price JS and Lanyon LE: Estrogen receptors' roles in the control of mechanically adaptive bone (re)modeling. Bonekey Rep 2: 413, 2013.

42. Ge L, Cui Y, Cheng K and Han J: Isopsoralen Enhanced Osteogenesis by Targeting AhR/ER $\alpha$. Molecules 23: 23, 2018.

43. Abdallah BM, Ditzel N, Mahmood A, Isa A, Traustadottir GA, Schilling AF, Ruiz-Hidalgo MJ, Laborda J, Amling M and Kassem M: DLK1 is a novel regulator of bone mass that mediates estrogen deficiency-induced bone loss in mice. J Bone Miner Res 26: 1457-1471, 2011. 